\title{
Tunable dual-band printed tab monopole antennas for wireless communications
}

\author{
Juan Valenzuela-Valdés, Miguel A. García-Fernández, Antonio M. Martínez-González and David Sánchez-Hernández \\ Departamento de Tecnologías de la Información y Comunicaciones. \\ Universidad Politécnica de Cartagena \\ Campus Muralla del Mar \\ E-30202 Cartagena Spain \\ E-mail: juan.valenzuela@,upct.es
}

\begin{abstract}
The advance of communication systems requires new antenna designs to comply with the ever-increasing demands of the wireless market. The antenna designs are being conditioned by miniaturization and migration to new frequencies (IEEE 802.11a/g), while keeping compatibility with other systems poses yet additional constrains. This contribution presents a novel monopole multi-band printed antenna design for WiFi systems, featuring the use of a spurline filter to obtain dual-frequency operation. Design constrains are discussed, along with simulated and measured results.
\end{abstract}

\section{INTRODUCTION (HEADING 1)}

Printed antennas have acquired a great importance thanks to their compatibility to high precision and low cost production techniques. Due to their inherently narrow bandwidth, however, their design and fabrication, either isolated or integrated in an array, requires high accuracy.

\section{THE DUAL-BAND ANTENNA SCHEME}

Several printed dual-band antenna have been previously developed at Universidad Politécnica de Cartagena and other research units. The techniques employed included a spur-line filter in the perimeter [1-4], in order to achieve a dual frequency operation without incrementing the overall size of the patch. The same technique has now been applied to the design of dual band printed monopole antenna.

The tab monopole [5] consists of a sub-wavelength tapered radiating element fed by a suitable transmission line and situated above a planar ground plane. The tab monopole has been designed to obtain a resonance at $5.5 \mathrm{GHz}$, which is necessary for operation under the IEEE $802.11 \mathrm{a} / \mathrm{g}$ standards. A spur-line filter embedded in its perimeter allows the operation at a new $2.4 \mathrm{GHz}$ resonance, which is also necessary for IEEE $802.11 \mathrm{a} / \mathrm{g}$.

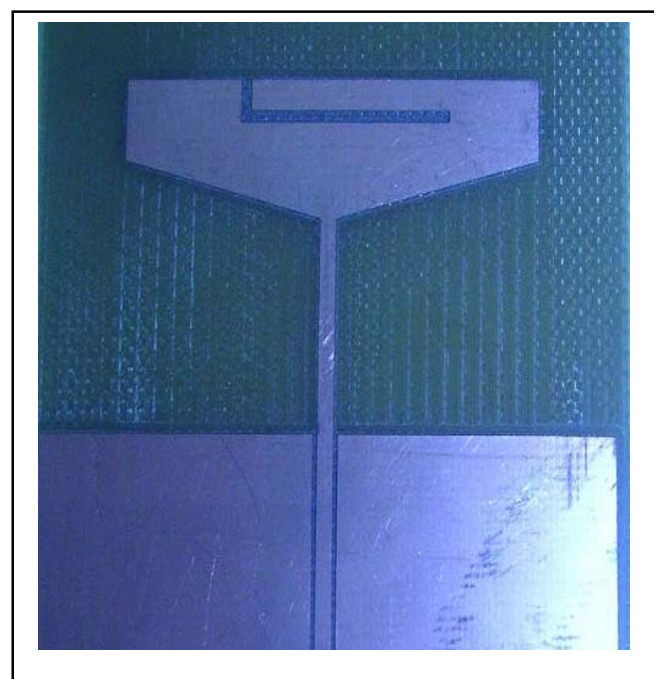

Figure 1. The dual band structure

Up to now the spur-line filter has been used as an additional narrowband technique for broadening conventional patches bandwidths [6-7]. This is now applied to an inherently broadband antenna, producing relatively large bandwidths. In particular, the modified tab monopole, depicted in figure 1, has been designed for wireless communications needing more than $10 \%$ bandwidth in the 5 $\mathrm{GHz}$ band.

Numerous metalized vias connecting the front and back are used in the prototype tab monopole in order to suppress spurious parallel plate modes that are known to occur in the grounded coplanar waveguide line. 


\section{SIMULATED AND MEASURED RESULTS}

To investigate the radiation and VSWR performance of the new antenna, the IE3D commercial EM-simulator is employed. The antennas have been made using the FR4 low cost substrate with a thickness of $1.524 \mathrm{~mm}$ and a dielectric constant of 4.27. Measurements are carried out using a HP8720B network analyzer.

Simulated and measured input return loss for the original tab monopole antenna at the natural resonance band is depicted in figure 2. A $14.7 \%$ simulated bandwidth (795 $\mathrm{MHz}$ at $\left.\mathrm{f}_{2}=5.425 \mathrm{GHz}\right)$ and $10.8 \%$ measured bandwidth $(600$ $\mathrm{MHz}$ at $\left.\mathrm{f}_{2}=5.55 \mathrm{GHz}\right)$ were attained with the $\mathrm{S}_{11}<-10 \mathrm{~dB}$ criterion for the original tab monopole design.

The spur-line filter consists of two coupled $\lambda_{\mathrm{g}} / 4$ microstrip lines, with an open circuit at the end of one of them and the other two extremes connected to each other. The resonance of spur-line filter is easy tunable, and this characteristic is translated into the novel antenna design, as it is illustrated in figure 3 for spur lengths between $-\lambda_{\mathrm{g}} / 20$ and $+\lambda_{\mathrm{g}} / 10$.

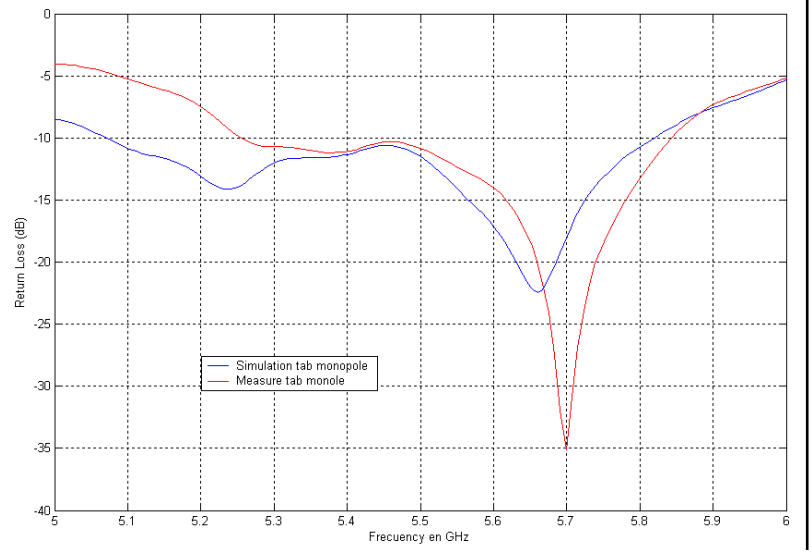

Figure 2. Simulated and measured input return loss in the $5 \mathrm{GHz}$ band.

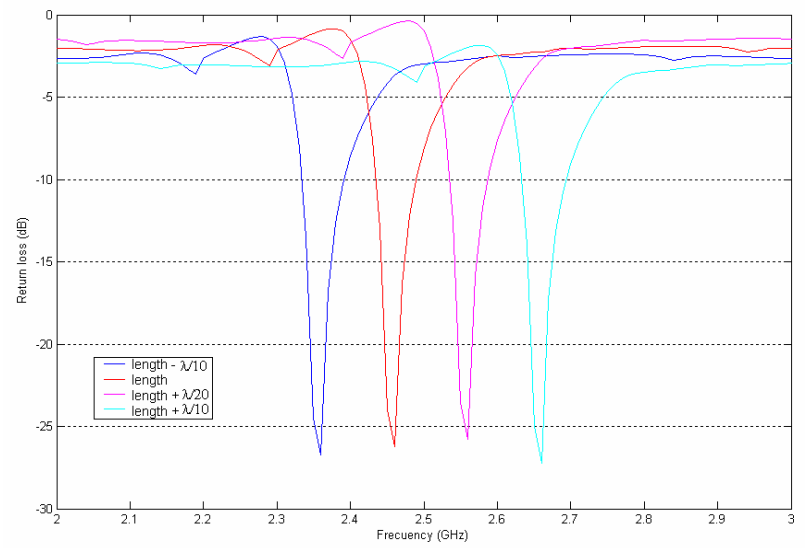

Figure 3. Simulated tunable input return loss in the $2.4 \mathrm{GHz}$ band.
The currents distributions and radiation patterns are show in figures 4 to 6 . The radiation patterns for the modified tab monopole are very similar to those of the original tab monopole [5].

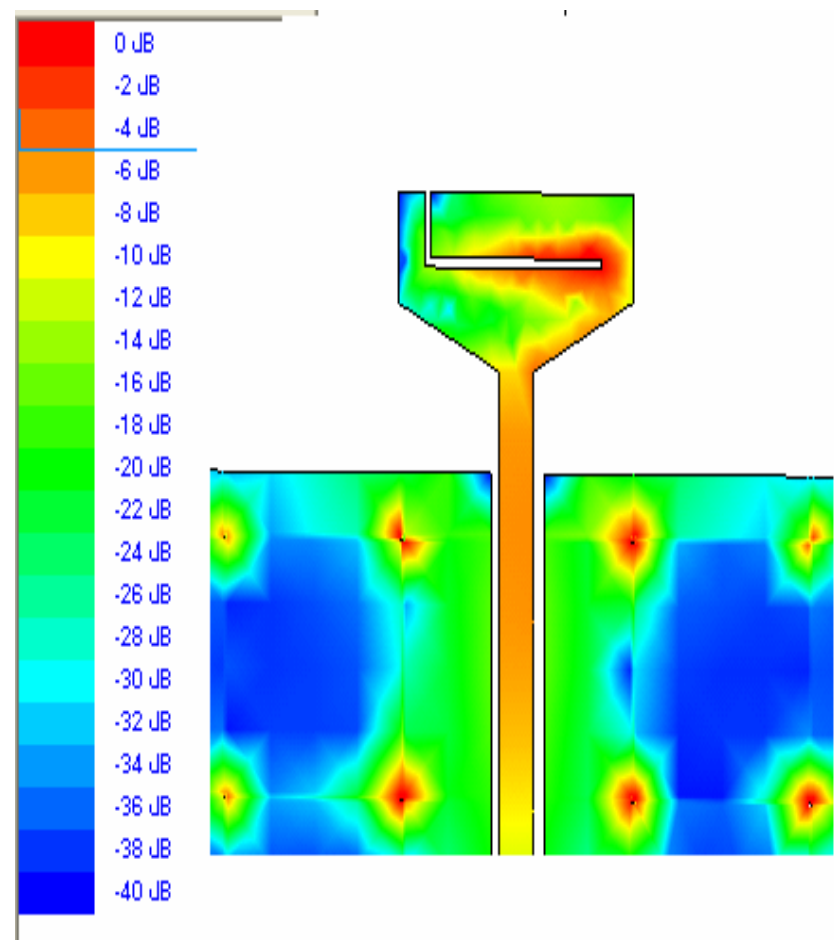

Figure 4. Simulated current distribution at $2.4 \mathrm{GHz}$

$=5.4(\mathrm{GHz})$, E-total, theta $=0$ (deg)

$\mathrm{f}=5.4(\mathrm{GHz})$, E-theta, theta $=0$ (deg), $\mathrm{PG}=-3.78274 \mathrm{~dB}, \mathrm{AG}=-5.79569 \mathrm{~dB}$ $\mathrm{f}=5.4(\mathrm{GHz}), \mathrm{E}-\mathrm{phi}$, theta $=0$ (deg), $\mathrm{PG}=-3.78274 \mathrm{~dB}, \mathrm{AG}=-5.68581 \mathrm{~dB}$

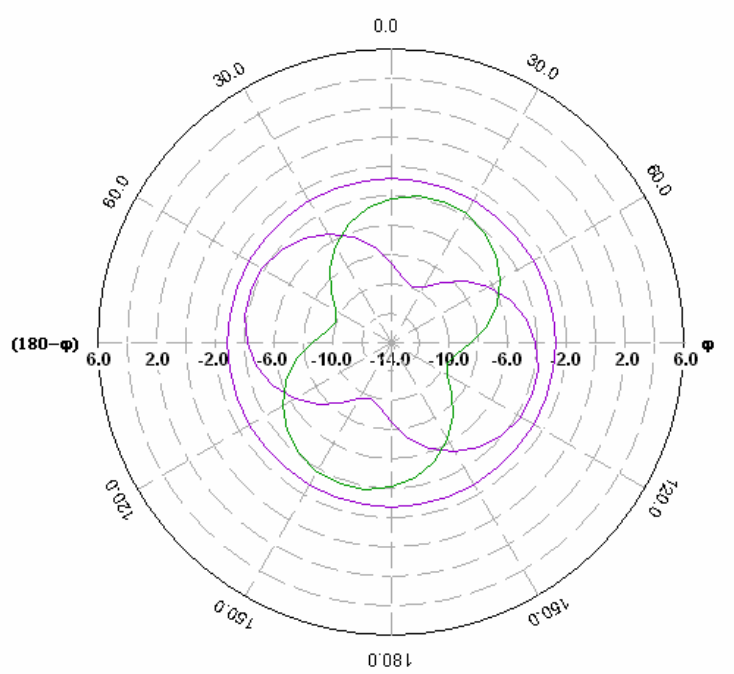

Figure 5. Simulated radiation patterns at $5.4 \mathrm{GHz}$ (acimut). 


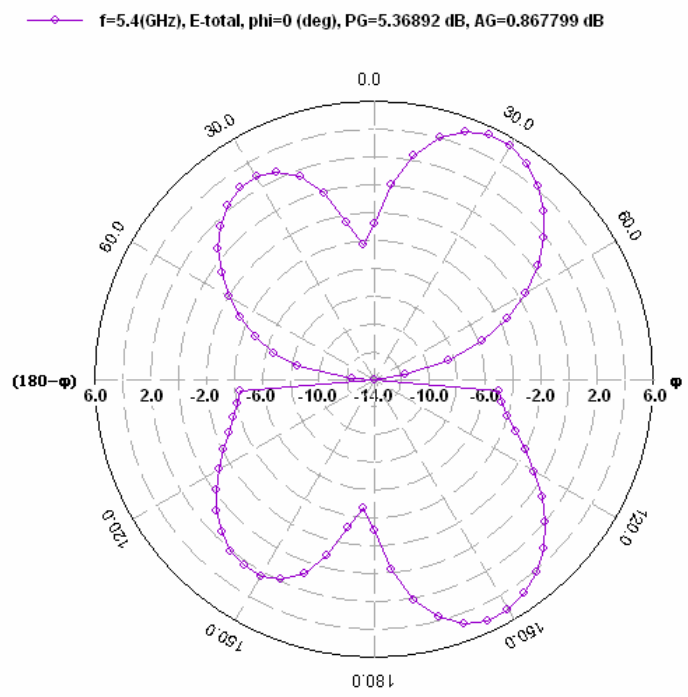

Figure 6. Simulated radiation patterns at $5.4 \mathrm{GHz}$ (elevation).

A consistent $1.85 \%$ difference between simulated and measured input return loss was encountered for the modified design, which is attributable to variation in dielectric constant of low-cost substrates and manufacturing limitations [8].

With these prediction errors accounted for, the measured input return loss measured for the final design is depicted in figure 7, wherein the operating bands fall within the required bandwidths for commercial WiFi systems. Final measured bandwidths of $4.9 \%\left(120 \mathrm{MHz}\right.$ at $\mathrm{f}_{1}=2.45 \mathrm{GHz}$ and $13.6 \%$ $\left(740 \mathrm{MHz}\right.$ at $\mathrm{f}_{2}=5.43 \mathrm{GHz}$ ) were attained for the modified tunable tab monopole.

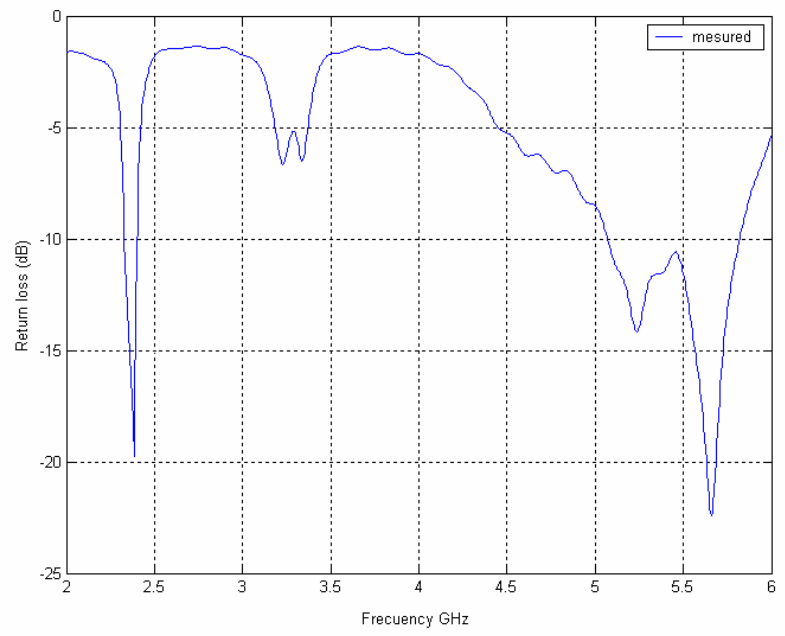

Figure 7. Final measured results for modified tab monopole.

\section{CONCLUSIONES}

The novel tunable dual-band antenna has shown excellent performance and bandwidth. This antenna can be used for commercial wireless communications systems like 802.11 a/g or Hiperlan2.

\section{ACKNOWLEDGMENT}

The authors would like to thank Bluetest $\mathrm{AB}$ for their generous educational discounting. This research work has been partially funded by The Spanish National R\&D Programme under the FIT-330210-2005-2 project.

\section{REFERENCES}

[1] Serrano-Vaello, Á. and Sánchez-Hernández, D., 'Printed antennas for dual-band GSM/DCS1800 mobile handsets', Electronics Letters, vol. 34, No. 2, pp. 140-141, Jan. 1998.J. Clerk Maxwell, A Treatise on Electricity and Magnetism, 3rd ed., vol. 2. Oxford: Clarendon, 1892, pp.68-73.

[2] Martínez-Vázquez, M., Martínez-González, A., Ávila-Navarro, E. and Sánchez-Hernández, D., 'Dual-band dual-mode printed bow-tie antennas integrated in handheld terminals for wireless communications', 28th European Microwave Conference, pp. 1-6, Oct. 1998.

[3] Lu, J-H. and Wong, K-L., 'Single-feed dual-frequency equilateraltriangular microstrip antenna with pair of spur lines', Electronics Letters, vol. 34, No. 12, pp. 1171-1173, Jun. 1998.

[4] Hammand, H.F., Antar, Y.M.M. and Freundorfer, A.P., 'Dual band aperture coupled antenna using spur line', Electronics Letters, vol. 33, No. 25, pp. 2088-2090, Dec. 1997.

[5] Johnson, J.M. and Rahmat-Samii, Y., 'The Tab monopole Antenna', IEEE Trans. on Antennas \& Propagation, vol. 45, No. 1, pp. 187-188, 1997.

[6] Martínez-González, A., Sánchez-Aguilar, M.A., Martínez-Vázquez, M. and Sánchez-Hernández, D., 'A comparison of dual-band spurline printed antennas for hand-held terminals', Microwave and Optical Technology Letters, vol. 30, pp. 205-207, 2001.

[7] Sánchez-Hernández, D. and Robertson, I.D., 'Analysis and design of a dual-band circularly polarized microstrip patch antenna', IEEE Trans. on Antennas \& Propagation, vol. 43, pp. 201-205, 1995.

[8] Martínez-Vázquez, M., Catalá-Civera, J.M. y Sánchez-Hernández, D., 'Quantification of errors in the prediction of resonant frequencies for printed antennas using commercial electromagnetic simulators through the utilization of measured substrate dielectric properties', Proceedings of the AP2000 Millennium Conference on Antennas \& Propagation, pp. 468. 